\title{
Availability of Personal Protective Equipment Among Health-care Workers in Jordan During the COVID-19 Pandemic: A Web-Based Survey
}

\author{
Arash Nemat $\mathbb{D}^{1,2}$ \\ Osama Alsarhan ${ }^{2}$ \\ Nahid Raufi $\mathbb{D}^{3,4}$ \\ Eva Inam Al Zein ${ }^{5}$ \\ Khalid A Kheirallah $\mathbb{1}^{6}$ \\ Mohammad Yousuf Mubarak (D) \\ 'Department of Microbiology, Kabul \\ University of Medical Sciences, Kabul, \\ Afghanistan; ${ }^{2}$ Department of Cardiology, \\ Nanfang Hospital, Southern Medical \\ University, Guangzhou, People's Republic \\ of China; ${ }^{3}$ Department of Dermatology, \\ Kabul University of Medical Sciences, \\ Kabul, Afghanistan; ${ }^{4}$ Department of \\ Dermatology, Guangdong Provincial \\ Dermatology Hospital, Southern Medical \\ University, Guangzhou, People's Republic \\ of China; ${ }^{5}$ Jordan Food and Drug \\ Administration, Amman, Jordan; \\ ${ }^{6}$ Department of Public Health, Medical \\ School of Jordan University of Science \\ and Technology, Irbid, Jordan
}

Propose: The inception of the COVID-19 has put health-care workers (HCWs) in a precarious situation across the world. In spite of the challenges in Jordan, the high awareness and preparedness of HCWs made it feasible for the country to control the contagious virus. The study aimed to provide a useful insight into availability of PPE among HCWs in Jordan, which could help the policy/decision-makers of public health to design better programs based on the information reported.

Methods: This cross-sectional online survey was conducted during July 2020 for the evaluation of the availability of personal protective equipment (PPE) among HCWs in Jordan.

Results: A total of $751 \mathrm{HCWs}$ responded from different parts of the country, who were actively working at different hospitals in Jordan. The majority of the participants (94\%) reported having sufficient knowledge about COVID-19 and more than two-thirds of participants $(68 \%)$ reported that PPE were provided by the Jordanian Ministry of Health. The majority $(91 \%)$ of participants reported availability of medical face masks, while only $26 \%$ reported having facial protective shields.

Conclusion: The study highlighted sufficient availability of PPE during the COVID-19 pandemic, which may have caused minimal infection rates among HCWs in Jordan.

Keywords: Jordan, coronavirus, pandemic, PPE, survey

\section{Introduction}

\section{Background}

COVID-19 is a global health concern which started in Wuhan, China. ${ }^{1}$ The novel coronavirus, SARS-CoV-2, is a highly transmissible virus that spreads from one person to another via respiratory droplets and aerosols. ${ }^{2}$ Countries across the world are taking preventative measures to control the spread of the virus. On the individual level; social distancing, using hand sanitizer, washing hands, and wearing masks are some of the measures taken to prevent the infection. ${ }^{3}$

In Jordan, the first case of COVID-19 was confirmed when a national infected case arrived from Italy early March $2020 .^{4}$ Since then, the government initiated a cascade of non-pharmaceutical interventions (NPIs) that included a strict lockdown and a curfew. ${ }^{5}$ The Jordanian government is strictly following the World Health Organization (WHO) recommendations to mitigate the spread of the virus. In Jordan, which is considered an upper middle-class country in the Eastern Mediterranean region, the health system is advanced in comparison to its 
neighboring Syria and Iraq. ${ }^{6}$ The country initiated the defense law early during the epidemic, March 2020, which mandated wearing masks among other precautionary measures. ${ }^{4}$ Jordan is considered a leading country in health-care services in the Middle East with many global ranks and awards. ${ }^{7,8}$ In the early days of the pandemic, one of the world's strictest lockdowns took place in the country and five tertiary hospitals were designated to provide medical care for suspected/diagnosed COVID-19 patients, in a short time the advanced medical care is provided across the country with about 12,081 beds capacity. ${ }^{9}$

The inception of the COVID-19 has put HCWs in a precarious situation across the world. ${ }^{10} \mathrm{HCWs}$, due to the inherent nature of their profession, are at particularly high risk of catching the COVID-19 infection. As of July 2020, the UN announced that, worldwide, over 1.4 million infections of COVID-19 were accounted for in HCWs; this was $10 \%$ of all cases. ${ }^{11}$ In spite of the challenges in Jordan, the high awareness and preparedness of HCWs might be extremely important to protect health settings and control the contagious virus. ${ }^{12}$

\section{Personal Protective Equipment (PPE)}

The HCWs and patients are exposed to infectious airborne products in the health settings, therefore, the use of PPE is a vital tool to promote patients safety and raise the safety of HCWs. ${ }^{13}$ PPE consist of face mask, face shields, goggles, gowns, head cover, and boot cover which creates an essential coverage from environmental toxic or infectious particles. ${ }^{14}$ In the light of the Center for Diseases Control and Prevention (CDC) recommendations the HCWs who deal with patients with confirmed or suspected COVID-19, must receive comprehensive training on when and what PPE is necessary, how to don (put on) and doff (take off) PPE, limitations of PPE, and proper care, maintenance, and disposal of PPE. ${ }^{15}$

\section{Objectives}

This report aims to evaluate availability of PPE among HCWs in Jordan, which could help the policy/decisionmakers of public health to design better programs based on the information reported.

\section{Materials and Methods}

A cross-sectional study was conducted to assess the availability of PPE among HCWs during the COVID-19 pandemic in Jordan. A non-probability convenience sampling technique was used to recruit the respondents. The inclusion criteria were being 18 years or older and having access to internet connection to fill out the online questionnaire. HCWs who do not consent to participate in the study were excluded.

The questionnaire, administered through the SurveyMonkey website, was distributed from July 21 to 23, 2020 by Jordanian health workers in Jordan through social media platforms (Facebook, WhatApp). A total of 751 Jordanian HCWs filled in the form. The questionnaire consisted of 10 questions in general and had three queries that were used for the purpose of demographics; age (18$24,25-34,35-44,45-54,55$, or $>55$ years); sex (male or female); and occupation (medical specialist, medical doctor/trainee, dentist, nurse, midwife, pharmacist, anesthesiologist, lab technician, physiotherapist, administration staff, and other health-care professionals). The rest questions were about availability of PPE, testing rate, and having COVID-19-related clinical symptoms. The SurveyMonkey website was used for sharing the questionnaire, and data analysis was conducted using SPSS version 25. Descriptive statistics and percentages were used to summarize the data.

\section{Results}

A total number of $751 \mathrm{HCWs}$ completed the online survey. Of them, $59 \%$ were females, about half (45\%) were medical doctors, $24 \%$ were nurses, $9 \%$ dentists, and $8 \%$ were pharmacists. More than half of participants (51\%) were between 25 and 34 years old (Table 1). Most of participants who filled in the survey link were from Irbid (35.9\%) and Amman (30.4\%) (Figure 1). The majority (91\%) of participants reported availability of medical face masks, about two-thirds reported having N95 masks (65\%), 64\% reported having disposable gowns, three quarters reported having boot cover (75\%), while only $26 \%$ reported having facial protective shields (Table 2).

More than two-thirds of participants $(68 \%)$ reported that PPE were provided by the Ministry of Health while about one quarter $(21 \%)$ reported that they provided their own PPE, and $11 \%$ accessed PPE from other sources (Figure 2).

The majority of the participants (94\%) reported that they have sufficient knowledge about COVID-19 (Figure 3).

Respondents reported their concerns during the COVID-19 pandemic as following: spreading the virus to the family members $(69 \%)$, catching the virus from patients (32\%), work overload (12\%), lack of appropriate 
Table I Demographic Characteristics of Health-care Workers

\begin{tabular}{|l|l|l|}
\hline Characteristics & Category & n (\%) \\
\hline Gender & Female & $38 I(59)$ \\
& Male & $370(4 I)$ \\
\hline \multirow{2}{*}{ Age } & 18 to 24 & $205(27)$ \\
& 25 to 34 & $383(51)$ \\
& 35 to 44 & $125(17)$ \\
& 45 to 54 & $31(4)$ \\
& 55 or more & $7(1)$ \\
\hline \multirow{2}{*}{ Medical Profession } & Medical doctor & $338(45)$ \\
& Dentist & $64(9)$ \\
& Nurse & $182(24)$ \\
& Pharmacist & $61(8)$ \\
& Midwife & $15(2)$ \\
& Anesthesiologist & $22(3)$ \\
& Lab technician & $46(6)$ \\
& Physiotherapist & $8(1)$ \\
& Administration worker & $15(2)$ \\
\hline
\end{tabular}

place for accommodation (10\%) and shortage of PPE (3\%) (Figure 4).

In response to the question of whether participants tested for COVID-19 (testing rate), the majority (96\%) of participants confirmed such, only the $4 \%$ indicated that they did not test for COVID-19. In regard to participants' COVID-19 related symptoms only a small proportion of participants (3\%) declared being symptomatic, whereas the majority of participants reported good health condition (Figure 5).

The following symptoms were reported among the 22 (3\%) symptomatic participants: fatigue $83 \%$, cough $71 \%$, sore throat $59 \%$, and headache $28 \%$.

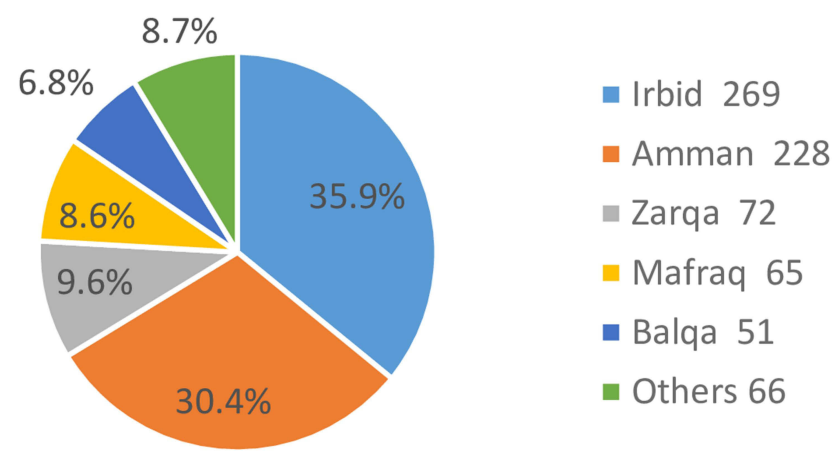

Figure I Geographical distribution of HCWs who participated in the study.
Table 2 Self-reported Availability of Essential Personal Protective Items

\begin{tabular}{|l|c|}
\hline PPE Item & n (\%) \\
\hline Medical mask & $68 I(90.6)$ \\
N95 masks & $489(65.1)$ \\
Disposable gloves & $671(89.3)$ \\
Goggles & $221(29.4)$ \\
Disposable gowns & $478(63.6)$ \\
Boot cover & $561(74.7)$ \\
Face shields & $199(26.5)$ \\
\hline
\end{tabular}

\section{Discussion}

COVID-19 in Jordan was, as many developing countries, faced with limited resources yet fast changing situation and epidemiologic curve. While Jordan seems to have delt with the pandemic early on, by implementing early lockdowns for around six months, the

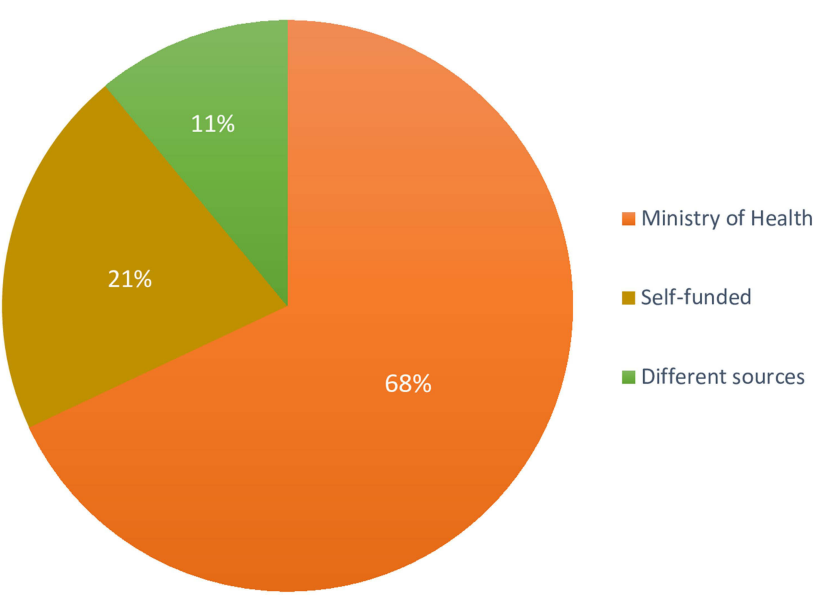

Figure 2 PPE sources for health-care workers in Jordan during the COVID-19 pandemic.

Yes, I have

No, I don't have

a don't know

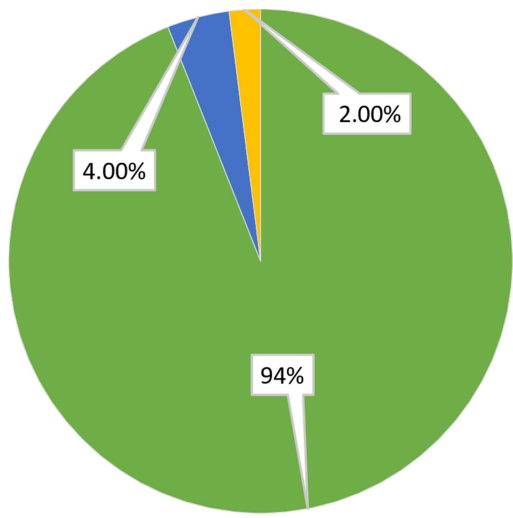

Figure 3 Having sufficient knowledge report about COVID-19 among study respondents. 


Spreading the virus to the family
members
Contracting the virus from patient
Work overload
Absence of suitable place for
accomodation
Shortage of PPE
Others

Figure 4 Main concern of HCWs during the COVID-19 pandemic.

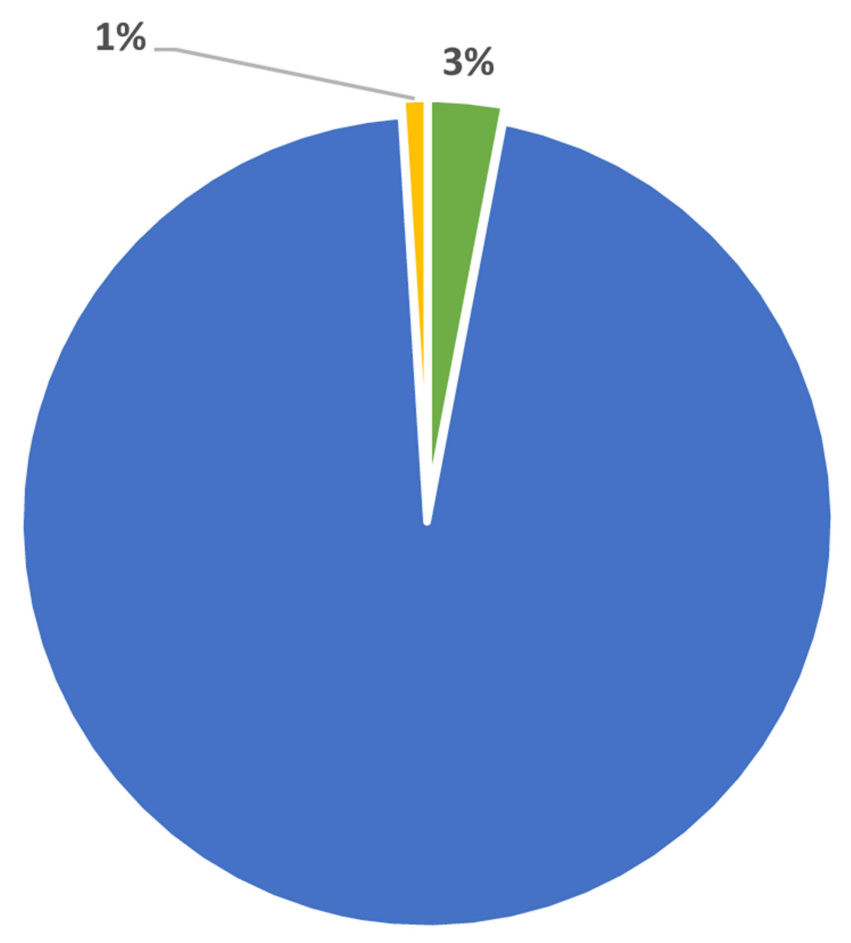

$96 \%$

\section{Yes $\square$ No $\square$ I don't know}

Figure 5 COVID-19 related symptoms reported by study respondents.

hospitalization rates were manageable to a degree yet the resilience of the health-care system was stretched to unprecedented levels.

This study investigated a sample of HCWs in regard to the availability of PPE and their main COVID-19 concerns

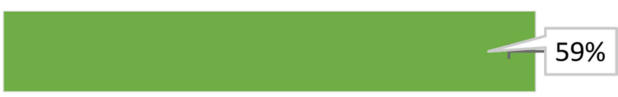

$39 \%$

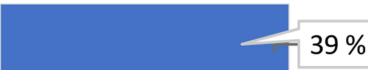

$12 \%$ $10 \%$

$3 \%$

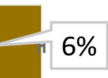

during the early stage of the pandemic in Jordan. It was found that HCWs in Jordan had high access to the PPE with a low, self-reported, SARS-CoV-2 infection rate (3\%). The advantage of investigating the preparedness of a country's health-care system allows them to navigate the importance of particular public health guidelines in the event of a health crisis. This enables policymakers to modify policies based on findings and recommendations. ${ }^{16}$ Each country has its own health-care response to outbreaks, thus developing different results of controlling any infectious disease. A big factor that plays into a health-care system is its HCWs, ${ }^{17}$ who make up a united front for well-planned management, especially in infectious diseases, thus having a better outcome in control.

A recent study done in Jordan reported that the preparedness of HCWs during the COVID-19 pandemic may be a major reason for the well-controlled outbreak in the country. ${ }^{18-20}$ The preparedness in terms of PPE adherence and institutional protocols led to a significantly higher percentage of satisfaction with feeling safe at their work, with feeling safe for their colleagues at work, and with the feeling that current infection control practices at their institution will decrease the risk for them and their colleagues to contract COVID-19. These feelings have an effect in producing a safer and more productive working environment, which is vital during a global crisis.

In this cross-sectional online survey, $751 \mathrm{HCWs}$ were enrolled from different governorates. The majority of the responders were medical doctors actively working in Jordanian hospitals. Our study indicates that most of the participants had the required equipment recommended by 
the WHO, particularly N95 masks. In our questionnaire, $(91 \%)$ of the participants reported that they have used medical masks, besides 491 (65\%) used N95 masks. In this survey-based study, we found that the majority of HCWs received PPE from the Ministry of Health. In contrast, only $21 \%$ provided their own, out of pocket, PPE. The study findings on the reality and perceptions about the safety and resources available for HCWs during the COVID-19 pandemic could inform medical institutional authorities about the need for urgent attention to the HCWs as an important valuable resource.

\section{Limitations}

The findings of this study could not be generalized because it is quite challenging to determine the universe under this study. The recruitment of participants wase based on their willingness to take part in the survey, Meanwhile their access to the internet and social networking applications also influenced the study outcomes. This study had a limited scope. Participants were asked to answer very specific questions that might not cover the whole condition of the personal safety of HCWs.

\section{Conclusion}

HCWs in Jordan seem to have good access to essential PPE during the COVID-19 pandemic, which caused minimal infection rates among $\mathrm{HCW}$ in Jordan and allowed the country to mitigate the infection during its early stage.

\section{Data Sharing Statement}

To ensure confidentiality of the participants and observe relevant ethical considerations, data cannot be shared publicly. However, data can be accessed upon request from Dr Khalid Kheirallah, Head of Department of Public Health, Medical School of Jordan University of Science and Technology via email: kkheiral@gmail.com.

\section{Ethical Approval and Consent}

This manuscript was part of a series of studies approved by the IRB of Hashemite University. Dr Kheirallah, the corresponding author, has been part of that team and served as the senior author for multiple publications on it. None of the authors at Hashemite were on the team preparing this manuscript and their roles did not fit as authors according to standard guidelines. This study was conducted conforming to the Declaration of Helsinki. All participants were informed of the purpose of the study and agreed to participate before filling in the questionnaire by confirming the agree button of the written consent statement.

\section{Acknowledgments}

The authors would like to provide their extreme appreciation to all health-care workers in Jordan for their efforts in fighting against the COVID-19 pandemic.

\section{Author Contributions}

All authors made significant contribution to the work reported, either in the conception, study design, execution, acquisition of data, analysis and interpretation, or in all these areas; took part in drafting, revising or critically reviewing the article; have agreed on the journal to which the article has been submitted; and agree to be accountable for all aspects of the work. All authors attest they meet the ICMJE criteria for authorship.

\section{Disclosure}

The authors report no conflicts of interest in this work.

\section{References}

1. Lucero-Prisno DE III, Ahmadi A, Essar MY, Lin X, Adebisi YA. Addressing COVID-19 in Afghanistan: what are the efforts and challenges? J Glob Health. 2020;10(2). doi:10.7189/jogh.10.020341

2. Meselson M. Droplets and aerosols in the transmission of SARS-CoV-2. N Engl J Med. 2020;382(21):2063.

3. Cowling BJ, Aiello AE. Public health measures to slow community spread of coronavirus disease 2019. J Infect Dis. 2020;221 (11):1749-1751. doi:10.1093/infdis/jiaa123

4. Al-Balas M, Al-Balas HI, Jaber HM, et al. Distance learning in clinical medical education amid COVID-19 pandemic in Jordan: current situation, challenges, and perspectives. BMC Med Educ. 2020;20:1-7.

5. Kheirallah KA, Alsinglawi B, Alzoubi A, et al. The effect of strict state measures on the epidemiologic curve of COVID-19 infection in the context of a developing country: a simulation from Jordan. Int $J$ Environ Res Public Health. 2020;17:6530. doi:10.3390/ijerph17186530

6. Al-Tammemi AB. The battle against COVID-19 in Jordan: an early overview of the Jordanian experience. Front Publ Health. 2020;8:188. doi:10.3389/fpubh.2020.00188

7. THE JORDAN TIMES. Jordan tops region as medical tourism hub. Available from: https://web.archive.org/web/20110617025513/http: www.jordantimes.com/?news=10589. Accessed October 27, 2021.

8. THE JORDAN TIMES. Five hospitals designated for quarantine, Covid-19 testing. Available from: https://jordantimes.com/news/ local/five-hospitals-designated-quarantine-covid-19-testing. Accessed October 27, 2021.

9. Medical Travel Award 2020. The IMTJ Medical Travel Award Winners in 2014. Available from: https://awards.imtj.com/results/ 2014-winners/. Accessed October 27, 2021.

10. Tan L. Preventing the transmission of COVID-19 amongst healthcare workers. J Hosp Infect. 2020;105(364-365):364-365. doi:10.1016/j. jhin.2020.04.008

11. DW.COM. Coronavirus latest; July, 2020. Available from: https://www. dw.com/en/coronavirus-latest-who-says-health-workers-account-for -10-of-global-infections/a-54208221. Accessed October 27, 2021. 
12. Alhalaiqa FN, Khalifeh AH, Al Omari O, Yehia DB, Khalil MMH. Psychological problems in a sample of Jordanian healthcare workers involved in caring for patients with COVID-19: a cross-sectional study. Front Psychol. 2021;12. doi:10.3389/fpsyg.2021.679785

13. Cudjoe KG, Martin V. Safe PPE use: protecting our nurses. Nurs Made Incred Easy. 2021;19:17-20. doi:10.1097/01.NME.0000732028.303 34.66

14. Livingston E, Desai A, Berkwits M. Sourcing personal protective equipment during the COVID-19 pandemic. JAMA. 2020;323: 1912-1914. doi:10.1001/jama.2020.5317

15. Centers for Disease Control and Prevention. Use Personal Protective Equipment (PPE) when caring for patients with confirmed or suspected COVID-19. Available from: https://www.cdc.gov/coronavirus/2019-ncov /downloads/A_FS_HCP_COVID19_PPE.pdf. Accessed October 27, 2021.

16. Sundararaman T. Health systems preparedness for COVID-19 pandemic. Ind $J$ Public Health. 2020;64:91. doi:10.4103/ijph. IJPH_507_20
17. Fusco F, Pisaturo M, Iodice V, et al. COVID-19 among healthcare workers in a specialist infectious diseases setting in Naples, Southern Italy: results of a cross-sectional surveillance study. $J$ Hosp Infect. 2020;105:596-600. doi:10.1016/j.jhin.2020.06.021

18. Suleiman A, Bsisu I, Guzu H, et al. Preparedness of frontline doctors in Jordan healthcare facilities to COVID-19 outbreak. Int J Environ Res Public Health. 2020;17:3181. doi:10.3390/ijerph17093181

19. Roya News. First coronavirus case in Jordan confirmed. Available from: https://en.royanews.tv/news/20134/2020-03-02. Accessed October 27, 2021.

20. Alhalaiqa FN, Khalifeh AH, Al Omari O, Yehia DB, Khalil MMH. Psychological problems in a sample of Jordanian healthcare workers involved in caring for patients with COVID-19: a cross-sectional study. Front Psychol. 2021;12:679785. doi:10.3389/fpsyg.2021.679785

\section{Publish your work in this journal}

Risk Management and Healthcare Policy is an international, peerreviewed, open access journal focusing on all aspects of public health, policy, and preventative measures to promote good health and improve morbidity and mortality in the population. The journal welcomes submitted papers covering original research, basic science, clinical \& epidemiological studies, reviews and evaluations, guidelines, expert opinion and commentary, case reports and extended reports. The manuscript management system is completely online and includes a very quick and fair peer-review system, which is all easy to use. Visit http://www.dovepress.com/testimonials.php to read real quotes from published authors. 